\title{
sciendo
}

DOI 10.2478/sbe-2021-0042

SBE no. 16(3) 2021

\section{BIG DATA ANALYTICS IN BASKETBALL VERSUS BUSINESS}

\author{
BRANGA Vlad-Alexandru \\ Lucian Blaga University of Sibiu, Romania
}

\begin{abstract}
:
Nowadays, because of the advancements in technology and the spread of globalization, information about game / player statistics or demographics of local and national workforce is only one click away. Information, or data, plays a very important role in basketball as it can make a difference in the selection process of players. On the other hand, human resources departments from various businesses can analyze big data from an internal (ex.: talent analytics) and external (ex. local and national demographics) perspective. Big data analysis is an activity that has gained more and more importance throughout time as it proved that it could help organizations make not only better decisions but also to better prepare for future games / negotiations. That is why, the purpose of this paper is to identify if and how basketball clubs and businesses - through their human resources department, use big data in order to attract and select the right people for their teams. More so, how big data is used in order to provide basketball clubs and businesses with a competitive advantage in the championship / on the market. By comparing how organizations such as basketball clubs use and interpret big data and how human resources departments of various businesses do it, some similarities but also big differences have been identified. Furthermore, the results also show that big data analytics can help basketball clubs and businesses to better identify the best-suited candidates for their teams. In conclusion, through the use of big data, basketball clubs and businesses can make more objective decisions regarding the people they recruit and how to develop them.
\end{abstract}

Key words: analytics, big data, basketball, human resources

\section{Introduction}

In today's market, organizations are continuously searching for new ways through which they can gain a competitive advantage. One way of doing this is through the gathering and interpretation of Big Data. Furthermore, Big Data Analytics has gained more and more importance in the past years and it has proven that it can be used by organizations such as basketball clubs and businesses as a competitive advantage if it is well analyzed, understood and applied. That is why, the purpose of this paper is to identify if and how basketball clubs and businesses - through their human resources department, use big data in order to attract and select the right people for their teams. More so, how big data is used in order to provide basketball clubs and businesses with a competitive advantage in the championship / on the market. This means that the 
researched topic is one of great importance for organizations (basketball clubs and businesses alike) that want to continuously evolve as it can give them that push they need in order to move forward / innovate.

\section{Literature Review}

In order to have a better understanding of the topic we first need to define what big data is. Mayer-Schönberger and Cukier state: "there is no rigorous definition of big data". (Mayer-Schönberger \& Cukier, 2013) However, they propose to regard this topic from the following point of view: "big data refers to things one can do at a large scale that cannot be done at a smaller one, to extract new insights or create new forms of value, in ways that change markets, organizations, the relationship between citizens and governments, and more." (Mayer-Schönberger \& Cukier, 2013) More so, De Mauro, Greco and Grimaldi view big data as "a term describing a social phenomenon, information assets, data sets, storage technologies, analytical techniques, processes and infrastructures." (De Mauro et al., 2016) As we can see, big data is not just about the volume of data, it also has other characteristics. The most important of these characteristics have been summed up under a concept called "The Three Vs" and is presented by Philip Russom as follows (Russom, 2011):

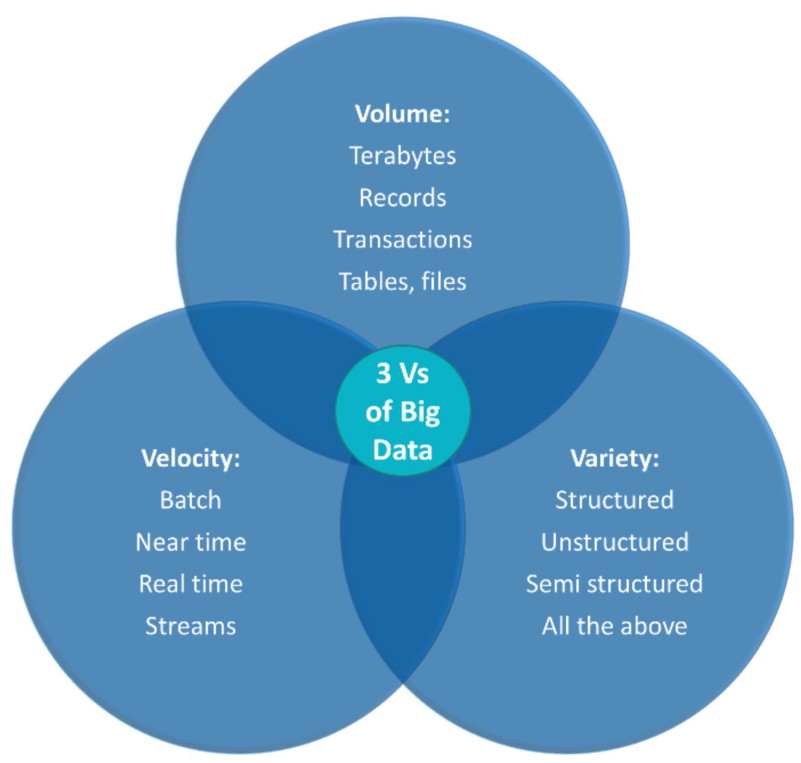

Figure 1. The Three Vs of Big Data

Source: Russom, P. (2011). Big data analytics. TDWI best practices report, fourth quarter, 19(4), 1-34.

Figure one above shows that big data, although having volume as its main characteristics, can be different from organization to organization. This means that there is not just one way to look at or analyze big data. In addition, another idea that we can clearly state is that big data is very different in regards to the information sources, data types and 
how they are organized. An important aspect to underline when working with big data is that it "is all about seeing and understanding the relations within and among pieces of information". (Mayer-Schönberger \& Cukier, 2013)

In addition, another important term to define would be "big data analytics". Loebbecke and Picot state: "we include the concept of big data analytics serving as a means to analyze and interpret any kind of digital information. Technical and analytical advancements in big data analytics, which - in large part - determine the functional scope of today's digital products and services, are crucial for the development of sophisticated artificial intelligence, cognitive computing capabilities and business intelligence." (Loebbecke \& Picot, 2015) This means that through gathering, organizing and analyzing big data organizations can be capable to develop themselves even further and gain a competitive advantage in their specific market.

Before moving on and answering the question of how basketball clubs and businesses gather, analyze and interpret big data, we must first clearly underline that an organization can organize its data into five types: Structured, Unstructured and Semi-structured, Internal and External. (Marr, 2015) Structured data (ex.: financial data, customer data) has as its main benefit the fact that it can provide us with a lot of insights about the organization. (Marr, 2015) Unstructured and semi-structured data on the other hand represent information (ex.: websites, images, videos, PowerPoint presentations and so on) that are not easy to organize in columns, rows or fields. (Marr, 2015) According to Marr, semistructured data can be viewed as a combination between the structured and unstructured. For example, this type of data has "some structure that can be used for analysis but lacks the strict data model structure." (Marr, 2015) Furthermore, regarding internal data, here we can add together every information that an organization has or can access such as customer feedback, sales information, stocks, employee information and more. (Marr, 2015) On the other hand, external data is defined as an infinite array of information that exists outside of the organization, for example: information about weather, government data, google maps and more. (Marr, 2015)

\section{Big data in Basketball}

In sports, mainly basketball, advancements in technology have led to an increase in players and teams performance. However, in order for the performance of players, and implicitly the teams to increase, data from all these new training gadgets needs to be collected, organized and analyzed. Examples of such training gadgets that are used nowadays and that provide players and coaches with a lot of information can be:

$\infty$ "basketballs with over 200 built-in sensors that provide the player and coaches with detailed feedback." (Marr, 2015);

$\infty$ "Blazepod" is another technological gadget that helps players improve their reaction time and provides coaches with an overview regarding how well a player can react in tense and rapid evolving situations during a game;

$\infty$ "HomeCourt" is a very beneficial app that can be used by basketball players all over the world and it analyzes their game while they play and provides them with 
instant feedback such as: shooting percentages overall and from specific areas on the court, release time and angle, legs movement and more;

$\infty$ Wearable biometric trackers;

All these gadgets and apps provide, as stated previously, basketball players and coaches with a lot of information. From the point of view of big data, all this information is already structured which is a big advantage; because it means that, it can be very easily analyzed. Furthermore, this type of information received by basketball players and coaches can also be considered as internal information as it is gathered from their own gadgets and analyzed by them directly. In addition, they have access to some similar external data. Player and team statistics are gathered at every game in the respective league in which a team plays. More so, basketball clubs can analyze as internal data:

$\infty$ Game attendance;

$\infty$ Consumer behavior;

$\infty$ Sales;

$\infty$ Fan Shop efficiency;

In regard with these internal big data, it is important to understand that simply to collect it is not sufficient. A data mining process is also needed. According to Mullin, Hardy and Sutton: "data mining can be defined as using powerful search tools to sift through and analyze consumer records". (Mullin et al., 2014) This process will then help basketball clubs "to determine patterns of consumer behavior that may lead to more efficient marketing activities. Data mining helps marketing and sales efforts by predicting which consumers may be more receptive to the offer being presented on the market." (Mullin et al., 2014) Moving on, external data in basketball is a lot bigger than the internal one. On the one hand, external data from the point of view of players and coaches, although structured, does not analyze a player's performance in so much detail as the internal one. This is the main difference between these two types of data that basketball clubs can access. Nevertheless, they do provide other types of information such as number of turnovers and steals. External data provided by league officially accepted software analyses statistics such as shooting percentages, turnovers, steals and many more. Again, this type of big data is structured and very easy to analyze and interpret, as it is accessible per game or per season. This gives basketball players and coaches the advantage of always being able to look over the numbers and make necessary adjustments in the training of the players and strategy of the team. On the other hand, external data for basketball clubs means information such as:

$\bullet$ game schedule;

$\infty$ locations;

$\infty$ rules and regulations of the league;

An interesting point of view that can sum up how important big data is to the progress of sport belongs to Millington: "But progress when it comes to sport and Big Data also means simply the pursuit of purportedly better knowledge. To reveal new insights-to make the invisible visible through data-is to allegedly excise the vagaries of subjective analysis." (Millington \& Millington, 2015)

Moreover, NBA Commissioner Adam Silver underlined the importance of big data analytics in an interview with Daniel Pink (author of "Drive" and "To sell is human") at Wharton 
People Analytics Conference in 2017 saying that: "Analytics have become front and center with precisely when players are rested, how many minutes they get, who they're matched up against." (Wharton, 2017) Silver also said that the NBA "is spending an increasing amount of time looking at data when it comes to injuries. Analytics might reveal information such as: If a particular player rests for three days after playing 30 straight games, there may be a greater likelihood he won't be injured." (Wharton, 2017) Basketball clubs in the NBA have started, for some years now, to invest heavily into the gathering and analysis of big data through partnerships with various companies that offer this type of services. Teams such as Dallas Mavericks, even have their own analytics team on which they rely on to make the team better. (Fox-Brewster, 2014) This proves how significant big data analytics is for basketball clubs.

\section{Big data in Business}

First, viewed from the business point of view, big data also includes terms such as "HR analytics" and "workforce analytics". A quote from Mark Huselid, Distinguished Professor of Workforce Analytics, Northeastern University, in the book "The Power of People: Learn how successful organizations use workforce analytics to improve business performance" written by Guenole and Ferrar underlines the importance of workforce analytics: "Industries are being disrupted. Talent is more mobile. All organizations need to understand the workforce better, and how it is executing the business strategy. And workforce analytics is at the heart of how to do this." (Guenole et al., 2017) In addition, because of big data analytics businesses can answer to strategic human capital questions that are important to the further development of the company. (Hamilton \& Sodeman, 2020) Similar to basketball big data in human resources can be categorized in internal (ex.: talent analytics) and external data (ex.: workforce demographics).

Second, similar to the situation in basketball, because of the advancements that big data analytics has made, businesses have found themselves forced to rethink their Human Resources strategies. This aspect has been proven by De Mauro et al who have identified through their research a number of four essential groups of job roles that have been created in the past years in the category of big data analytics (De Mauro et al., 2018):

$\infty$ Business Analysts (Business-facing analysts, project/program managers, Business advisors)

$\infty$ Data Scientists (Quantitative analysts, Statisticians, Modelers)

$\infty$ Developers (BI coders, Machine learning implementers)

$\bullet$ System Managers (Architects, Infrastructure Admins)

This aspect shows that businesses have not only recognized the importance of big data analytics for their future but also started to implement it. Of course, a business needs to generate a lot of data in order for it to be able to gather, organize and analyze it. One way in which businesses use big data analytics is to identify potential candidates that have the right skills and experience. (McLean et al., 2016) Conducting this type of talent analytics will provide them with a more objective decision as to hire someone or not. Moreover, businesses face the challenge of competing for workforce on the market, which is also applicable for their existing employees. In order to retain their employees from 
leaving, businesses can use big data analytics to find out in advance what they need to change in order to keep their employees from leaving. (Nocker \& Sena, 2019) Another way in which businesses can use big data in connection to their human resources department is regarding the learning and development of their employees. Similar to the term "talent analytics", there is also the term "learning analytics" which according to Seufert et al "can enable learners, teachers, and their institutions to better understand and predict learning and performance". (Seufert et al., 2019) Although the idea is regarding learning institutions, because businesses nowadays need to invest in the learning and development area of their employees, we can extrapolate the idea that businesses need to analyze these processes in order to offer the most well suited learning and development options for their employees. This in turn will not only lead to an increase in the retention of their employees but also in a positive employer branding, which, will lead to attracting the best suited candidates. In addition, concerning learning, big data can help businesses identify and develop behavioral patterns. Further, we can also state that workforce analytics is a topic that is more and more needed in businesses because its relevance will continue to grow as the "world of work will change in the future." (Guenole et al., 2017) In this regard, we can conclude that big data analytics in business is important all the step of the way. However, I would emphasize that it is best used in the planning stage as it can ensure a more efficient process.

Moreover, in business, similar to basketball, there are some technical gadgets and other software apps that can be used to gather data about the activity of employees. For example, nowadays employees get a badge that they use as an access and a time card. This means that the company can control their access and can see the working hours of an employee. However, they do not see if the employee is productive the whole time or just wastes time on social media. For example, there are options such as video surveillance through which one can identify if an employee takes to many breaks without registering them or if they simply waste time in non-productive talks with other employees. There are also software solutions to check if an employee is staying at the desk surfing the whole working day on social media or if they are using the computer in personal purposes. Now, these so-called solutions raise several ethical questions and problems that will need to be addressed through further distinct research on the topic.

\section{Findings}

Through the research for this paper, by comparing how organizations such as basketball clubs use and interpret big data and how human resources departments of various businesses do it, some similarities but also big differences have been identified. For example, similarities between the two researched areas include:

$\infty$ The importance of big data analytics has continuously grown which has been proven by the fact that basketball clubs and businesses alike have allocated specific job roles for this.

$\infty$ Retention of basketball players and employees can improve through the use of big data analytics. On the one hand, in basketball, this is an aspect that occurs rather indirectly because if players see that the club is investing in big data 
analytics it shows them that the club cares about their wellbeing and they might look for a long-term stay at the club even if they get better financial offers. On the other hand, the use of "workforce analytics" by businesses can show them for example exactly why people have a tendency to leave the company and then, they can act upon this aspects and improve them.

$\infty$ Both researched areas include same type of data, meaning they both rely on internal and external data.

At the same time, differences between the two researched areas include:

$\infty$ In basketball, data comes more from technical gadgets and is already structured into specific categories, which is not the case with big data in the human resources department where data needs to be prepared after gathering in order to be analyzed.

$\infty$ Through the analysis of big data, basketball clubs can easily determine if a player is "overplayed" and the chances of them gaining an injury high. In human resources on the other hand, we talk about employee burnout as something similar. However, although employee burnout can be foreseen through to the use of big data analytics, it is not as easy to determine as the injury probability in basketball. The reason being is that the type of information needed to determine this aspect is not so easily quantifiable (ex.: work-life balance of an employee).

$\infty$ There is also a difference regarding the "learning analytics". In business, learning analytics can be used to provide the company with an overall image regarding what soft skills their employees possess and which need to be further developed. Here we can include as an example the reasons for losing clients / contracts, which are easily quantifiable. In basketball, on the other hand, it is quite difficult to determine through the use of big data what soft skills a player needs to improve. One way to do this would be through questionnaires sent to their teammates in which they evaluate a specific player. However, this is a subjective analysis that contradicts the objective nature of big data analytics.

$\infty$ Another difference is regarding the structure of the data. In basketball the information that is gathered is a lot more structured as in human resources as it is gathered directly on specific key aspects of a player.

Furthermore, another interesting aspect that I found is that, regardless of the topic it is gathered on, data is not useful if meaning and value cannot be extracted from it. As Kitchin wrote: "In other words, it is what is done with data that is important, not simply that they are generated." (Kitchin, 2014) This means that by using big data analytics, basketball clubs and business can ensure a raise in value meaning that their players and employees will be more efficient.

\section{Conclusion}

Finally, we can conclude that what big data actually does, and what is represented as its main advantage, is to provide an objective point of view on the topic it has been gathered. More so, big data does not take into account the human factor, in the end it is just data. However, I think that if big data is used in an ethical manner, basketball clubs 
and businesses can manage to improve not only their players / employees but also their entire organizations as a whole. This objective point of view will provide them with a competitive advantage in the championship / on the market and it will improve their attractiveness as an employer.

\section{References}

De Mauro, A., Greco, M., \& Grimaldi, M. (2016). A formal definition of Big Data based on its essential features. Library Review.

De Mauro, A., Greco, M., Grimaldi, M., \& Ritala, P. (2018). Human resources for Big Data professions: A systematic classification of job roles and required skill sets. Information Processing \& Management, 54(5), 807-817.

Fox-Brewster, T. (2014). Big Data - revolutionising sport in unexpected ways. The Guardian. Retrieved 15.10.2021 from https://www.theguardian.com/technology/blog/2014/oct/06/bigdata-revolutionising-sport-in-unexpected-ways

Guenole, N., Ferrar, J., \& Feinzig, S. (2017). The power of people: Learn how successful organizations use workforce analytics to improve business performance. FT Press.

Hamilton, R., \& Sodeman, W. A. (2020). The questions we ask: Opportunities and challenges for using big data analytics to strategically manage human capital resources. Business Horizons, 63(1), 85-95.

Kitchin, R. (2014). The data revolution: Big data, open data, data infrastructures and their consequences. Sage.

Loebbecke, C., \& Picot, A. (2015). Reflections on societal and business model transformation arising from digitization and big data analytics: A research agenda. The Journal of Strategic Information Systems, 24(3), 149-157.

Marr, B. (2015). Big Data: Using SMART big data, analytics and metrics to make better decisions and improve performance. John Wiley \& Sons.

Mayer-Schönberger, V., \& Cukier, K. (2013). Big data: A revolution that will transform how we live, work, and think. Houghton Mifflin Harcourt.

McLean, S., Stakim, C., Timner, H., \& Lyon, C. (2016). Big data and human resources: Letting the computer decide. Scitech Lawyer, 12(2), 20.

Millington, B., \& Millington, R. (2015). 'The datafication of everything': Toward a sociology of sport and big data. Sociology of Sport Journal, 32(2), 140-160.

Mullin, B. J., Hardy, S., \& Sutton, W. (2014). Sport marketing 4th edition. Human Kinetics.

Nocker, M., \& Sena, V. (2019). Big data and human resources management: The rise of talent analytics. Social Sciences, 8(10), 273.

Russom, P. (2011). Big data analytics. TDWI best practices report, fourth quarter, 19(4), 1-34.

Seufert, S., Meier, C., Soellner, M., \& Rietsche, R. (2019). A pedagogical perspective on big data and learning analytics: A conceptual model for digital learning support. Technology, Knowledge and Learning, 24(4), 599-619.

Wharton. (2017). The NBA's Adam Silver: How Analytics Is Transforming Basketball. Wharton University of Pennsylvania. Retrieved 14.10.2021 from https://knowledge.wharton.upenn.edu/article/nbas-adam-silver-analytics-transformingbasketball/

https://blazepod.eu/

https://www.homecourt.ai/ 